Published as: Fransen, K., Neutens, T., Farber, S., De Maeyer, P., Deruyter, G. \& Witlox, F. (2015). Identifying public transport gaps using time-dependent levels. Journal of Transport Geography, vol. 48, p. 167-187.

\title{
Identifying public transport gaps using time-dependent accessibility levels
}

Koos FRANSEN*,a,b, Tijs NEUTENS ${ }^{b}$, Steven FARBER ${ }^{c}$, Philippe DE MAEYER ${ }^{b}$, Greet DERUYTER ${ }^{\mathrm{a}, \mathrm{b}}$, Frank WITLOX

a Department of Industrial Engineering, Ghent University, Valentin Vaerwyckweg 1, 9000 Ghent, Belgium

${ }^{b}$ Department of Geography, Ghent University, Krijgslaan 281 S8, 9000 Ghent, Belgium

${ }^{c}$ Department of Human Geography, University of Toronto Scarborough, 1265 Military Trail Toronto, ON, Canada

*Corresponding author: +32 0924888 16, Koos.Fransen@UGent.be, Krijgslaan 281 S8, 9000 Ghent, Belgium

\begin{abstract}
One of the concerns that has aroused much scholarly attention in transport geography lately is the extent to which public transport provision enables the less privileged population segments, especially those without privately owned motorized vehicles, to participate in activities that are deemed normal within the society they live in. This study contributes to this line of inquiry by proposing a methodology for identifying public transit gaps, a mismatch between the socially driven demand for transit and the supply provided by transit agencies. The methodology draws on the latest accomplishments in the field of modeling time-continuous, schedule-based public transport accessibility. Accessibility levels to key destinations are calculated at regular time intervals, and synoptic metrics of these levels over various peak and off-peak time windows are computed for weekdays and weekends. As a result, a temporally reliable picture of accessibility by public transport is constructed. The obtained index of public transport provision is compared to a public transport needs index based on the spatial distribution of various socio-demographics, in order to highlight spatial mismatches between these two indices. The study area consists of Flanders, which is the northern, Dutch-speaking region of Belgium. The results indicate that mainly suburban areas are characterized by high public transport gaps. Due to the time-variability of public transport frequencies, these gaps differ over time.
\end{abstract}

\section{Keywords}

Transport gap, transport disadvantage, social exclusion, public transport, GIS, Flanders 


\section{Introduction}

The past two decades have witnessed a large and growing academic and policy interest in the social implications of transport planning alongside the traditionally well-studied economic and environmental outcomes (Lucas, 2012). Understanding the ways in which inadequate or lack of mobility can contribute to social disadvantage and isolation has been brought to the forefront of the transport policy agenda. Currently, there is a wide recognition that transport policies may generate spatially and temporally uneven accessibility effects that unduly favor certain population groups above others (Grengs, 2015).

One of the concerns that has recently aroused much scholarly attention is the extent to which public transport provision enables the less privileged population segments, especially those without privately owned motorized vehicles, to participate in activities that are deemed normal within the society they live. Various studies conducted under the umbrella domain of transportrelated social exclusion have used geographical information systems (GIS) to unravel the connections between social disadvantage, public transport needs and public transport provision. However, much of the empirical work to date has explored these connections by examining social disparities in access to the public transit system rather than by the transit system. For example, in their assessment of the impact of bus network changes on different social groups in Northern Ireland, Wu and Hine (2003) suggested the use of public transport accessibility levels (PTAL) which essentially express accessibility as the sum of walking time to the closest bus stop plus average waiting time at that stop. Likewise, Currie (2010) applied a combined indicator of access to public transit stops (e.g. spatial coverage of walk catchments around public transport stops/stations) and their relative service (e.g. the number of bus/tram/train vehicle arrivals per week). While such indicators are insightful in identifying socio-spatial differences in access to the public transport system, they do not provide insights into whether the system brings people to desired activity locations within an acceptable travel time at the desired time of day. Furthermore, these indicators ignore that inadequate proximity to public transport provision can be compensated by local availability of amenities. Other recent studies that link transit access to social disadvantage like Delmelle and Casas (2012) assumed that public transport vehicles ride at a constant travel velocity in order to be able to construct a routable walk-transit network layer. Their multimodal approach accounted for ingress and egress time, but ignored wait and transfer times leading to an underestimation of the overall journey travel time. Other cognate studies have calculated end-to-end travel times by public transit using bespoke database software tools such as Amelia (Mackett et al., 2008) and Accession (Preston and Raje, 2007). While these tools have proven useful in aiding transport planners in the UK to compare the impact of policy actions, they are unavailable to the wider academic public. Furthermore, they offer rather limited flexibility to analysts in order for them to develop their own procedures on top of the functionalities embedded in the software. The accessibility metrics produced by these tools are therefore static in the sense that they describe what is accessible by public transit from a particular origin at a single point in time but do not consider the temporal variability in accessibility levels. Such temporal variability occurs as a consequence of fluctuations in operating frequencies across the diurnal cycle and between weekdays and weekends.

This study contributes to the strand of literature outlined above. It puts forward a methodology for identifying public transit gaps by drawing on the latest accomplishments in the field of modeling time-continuous, schedule-based public transport (Farber et al., 2014; Lei and Church, 2010; Owen and Levinson, 2014). It measures accessibility levels to key destinations for socio-spatial population groups at regular time intervals and computes synoptic metrics of these levels over various peak and off-peak time windows on weekdays and weekends. The obtained metrics of transport provision are then compared across social cross-sections of the population and compared to a public transport needs index to highlight spatial mismatches between provision and need. The study area consists of Flanders, which is the northern, Dutch-speaking region of Belgium. This region constitutes an interesting and challenging setting for studying public transport gaps since it is characterized by a highly dense public 
transport infrastructure with a variety of public transport alternatives run by different operators. Furthermore, since 2001 the region has adopted a clear-cut stance towards combatting transport poverty. Flanders is one of the only regions in the world ${ }^{1}$ where the right to basic provision to public transport, formulated as having spatial access to a minimum level of public transport service irrespective of the location of residence, is granted by law (decree 'Personenvervoer'). Within this context, budgetary pressure has prompted the public transport company $D e$ Lijn to search for new cost-effective alternatives (e.g. mobility budgets and neighborhood buses) to continue guaranteeing sufficient service in all parts of the region. The results reported in this study have served to set the stage and inform De Lijn about the deficits in coverage of their system in Flanders.

The paper proceeds with a brief review on the measurement of transport gaps and discusses how accessibility by public transport was modeled in prior work. Subsequently, it contextualizes the research within the study area and describes the data and methodology. The results are presented in Section 4. The paper concludes with the major findings and outlines avenues for further research.

\section{Literature review}

\section{Measuring public transport gaps}

Policy concerns related to social disparities in mobility and access to essential goods and services have emerged and grown in tandem with a wider policy interest in the causes and effects of social exclusion. Policy interest in social exclusion originated in the United Kingdom in the late 1990s as part of a broader social welfare reform under the New Labour government. A Social Exclusion Unit (SEU) set up in 1997 has sparked off a series of policy documents including a widely applauded report that focuses on the interactions between social disadvantages and transport disadvantages and how these interactions can culminate into situations of transport poverty and exclusion. Since the publication of the report, researchers from around the world have built up empirical evidence of social exclusion as a result of transport problems. Evidence has mounted in Europe (Priya and Uteng, 2009; Schönfelder and Axhausen, 2003), North America (Farber et al., 2011; McCray and Brais, 2007; Paez et al., 2010), Latin America (Delmelle and Casas, 2012; Jaramillo et al., 2012), Australia (Delbosc and Currie, 2011; Stanley and Vella-Brodrick, 2009), and Africa (Lucas, 2011; Porter et al., 2012).

Within this emerging body of international literature much attention has been devoted to the quality of public transport and more specifically to designating individuals and areas that suffer from public transport deficiencies. However, quantifying to what extent a person suffers from public transport deficiencies is difficult because transport poverty manifests itself at the individual and household level, whilst appropriate data sets are generally available at a zonal level (Hine and Grieco, 2003; Karner and Niemeier, 2013). Furthermore, it is difficult to determine when a person is to be considered transport poor. By definition (Lucas, 2012, p. 106), this has to do with the inability to access a 'normal' range of activity locations, but the exact meaning of such a 'normal range' remains absent, apart from it being the range of activities that is available to the majority of people in society (Levitas et al., 2007). The necessity of being able to reach certain destinations evidently differs for each individual and in different societies. Having access to education, for example, is more important to students than to the elderly, whereas the opposite may be true for health care. Hence, it is up to the analyst to judiciously decide which destinations matter in the case study at hand. Another issue is the definition of the concepts 'access' and 'inability to access' and whether these have to be conceptualized in normative or relative terms. 'Normative' refers to an absolute threshold that represents policy makers' expectations about the minimum required level of accessibility, while

\footnotetext{
${ }^{1}$ In the UK, local transport authorities are required to publish accessibility assessment reports as part of their Local Transport Plans Atkins, 2012. Accessibility Planning Policy: Evaluation and Future Direction - Final Report (2012).
} 
'relative' pertains to a particular benchmark (e.g., a population average) that expresses the accessibility levels of other individuals in the same society (Paez et al., 2012).

A common strategy to quantify socio-spatial deficits in public transport provision is to construct and compare two indices: one that expresses public transport needs and another that represents public transport provision. The former is composed of indicators that describe areabased populations who are most in need of public transport on the basis of such variables as car ownership, income, employment and age. The latter is an index representing how well an area is serviced by the public transport system. The difference between both indices is then termed the 'transport gap' which acts as a proxy for an area's vulnerability to developing transport poverty. Of particular interest are those areas with low provision and high need as well as those with low need and high provision as these cases represent situations of underservice and over-service, respectively. Exemplary to this approach is the work by Currie (2010) who found significant spatial patterns of 'high need - low provision' in Metropolitan Melbourne (Australia). Those patterns were also detected in Santiago de Cali (Columbia) by Jaramillo and colleagues (2012) using a similar methodology. The constructed disadvantage-impedance index by Duvarci et al. (2015) aims to counteract transport disadvantages by simulating the effects of potentially efficient policy alternatives in Arao, Japan. Aggregation errors notwithstanding, these studies help to understand the relative spatial scale of public transport shortfalls which can help inform policy makers regarding the spatial prioritization of transport policy actions. For this reason, a similar research strategy is adopted in this study.

\section{Modelling public transport accessibility}

Modelling public transport accessibility has a long history with a trend towards increasingly sophisticated measurements. At least four types of indicators of public transport accessibility can be identified. The first type measures the physical accessibility to the public transport system in terms of the proximity to transit stops in time or distance (Lei and Church, 2010). A commonly applied indicator is the walking distance from the centroid of an administrative unit to a public transport stop. An archetype of such indicator can be found in a study by Gutierrez and Garcia-Palomares (2008), who determined public transport coverage of interurban buses in Madrid. While simple and easily computed, proximity indicators offer only an incomplete picture of public transport accessibility as they disregard the service offered at each of the stops, the desired destinations within reach and the travel time to these destinations (Mavoa et al., 2012).

A second type of indicator additionally accounts for the importance of the public transit stops within the overall transit network. To that end, service frequencies at transit stops are often summarized per stop. To estimate transit equity in the Washington-Baltimore region (US), Welch and Mishra (2013) incorporated public transport frequency as an attribute that varies distinctly between peak and off-peak commuting times in a multi-modal transportation network. Third, in addition to physical accessibility to the transit system and the level of service offered by the system, some indicators account for the time or cost associated with the journey to the considered destinations. This requires the construction of a routable transportation network as well as the implementation of bespoke GIS procedures. Benenson et al. (2011), for example, developed the Urban.Access ArcGIS extension tool, which combines congestion-based realworld estimates of travel speed with bus schedules. This tool enabled to estimate car-based and transit-based accessibility to employment and other land uses and compare accessibility levels by transport mode in Tel-Aviv, Israel in an investigation of modal equity. Lei and Church (2010), for their part, proposed a GIS data structure to estimate the bus service time as the temporal dimension in a transit accessibility analysis in Santa Barbara, California. They also account for the time of day of the analysis by designating a specific departure or arrival time at one origin or destination respectively. The studies mentioned above are able to delineate which locations are reachable within a certain time budget, but they do not consider the number and type of opportunities within reach. Hence, certain studies additionally described access to specific location types. The simplest indicator is the number of a particular type of 
opportunity (e.g. jobs, schools, healthcare facilities etc.) available within a predetermined transit travel time. To assess the inter-modal equity by regional transportation, Golub and Martens (2014) applied a cumulative-opportunity approach that sums the number of essential destinations within predefined travel-time buffers by transit and automobile.

However, travel times by public transit fluctuate over time, and hence accessibility provided by the public transportation network is strongly influenced by the departure time (Lei and Church, 2010). To this end, a fourth and most sophisticated type of indicators has been developed to account for the temporal variability in public transit accessibility. Such indicators adopt a detailed door-to-door approach and consider the temporal (mis)matches between individuals' time budget in relation to transit timetables (e.g. Salonen and Toivonen, 2013). An important technical improvement in this respect includes General Transit Feed Specification files (GTFS) which allow construction of a multimodal public transport network dataset. GTFS is increasingly gaining attention from transport geographers. Hadas (2013) used GTFS to develop a GIS-based model enabling decision makers to (geo-)statistically analyze the connectivity within public transport networks. The model performed travel time analysis by incorporating published timetables based on average travel speeds of public transport vehicles. Other recent studies have applied GTFS data to construct a fully routable multimodal transportation network that enables estimating transit travel times at different times of the day (Farber et al., 2014; Ma and Jan-Knaap, 2014; Owen and Levinson, 2014).

Simultaneously with the emerging policy interest in the causes as well as the effects of social exclusion, the literature outlined above clearly exhibits an evolution from basic metrics focusing on physical accessibility to more refined analysis methods. The paper builds on the most sophisticated approach outlined above in order to contribute to the increasing complexity of public transport accessibility analysis. Therefore, a time-continuous and schedule-based methodology was applied to identify transport gaps. As a result, a temporally reliable picture of accessibility by public transport is constructed, as is explained in Section 4.

\section{Study area and data}

\section{Study area}

The study area consists of Flanders, a densely populated region in the northern, Dutchspeaking part of Belgium, Europe. The region has a population of approximately 6.4 million inhabitants in an area of $13,597 \mathrm{~km}^{2}$ and is divided in 308 municipalities, with strong concentrations in the cities of the larger agglomerations. Because of its central location and being a significant destination for Flemish travelers, destinations within Brussels and Wallonia (the southern, French-speaking part of Belgium) have also been considered in the analysis despite not being a part of Flanders. Both Flanders and Brussels have a higher population density in comparison to Wallonia located to the south (Fig. 1). 


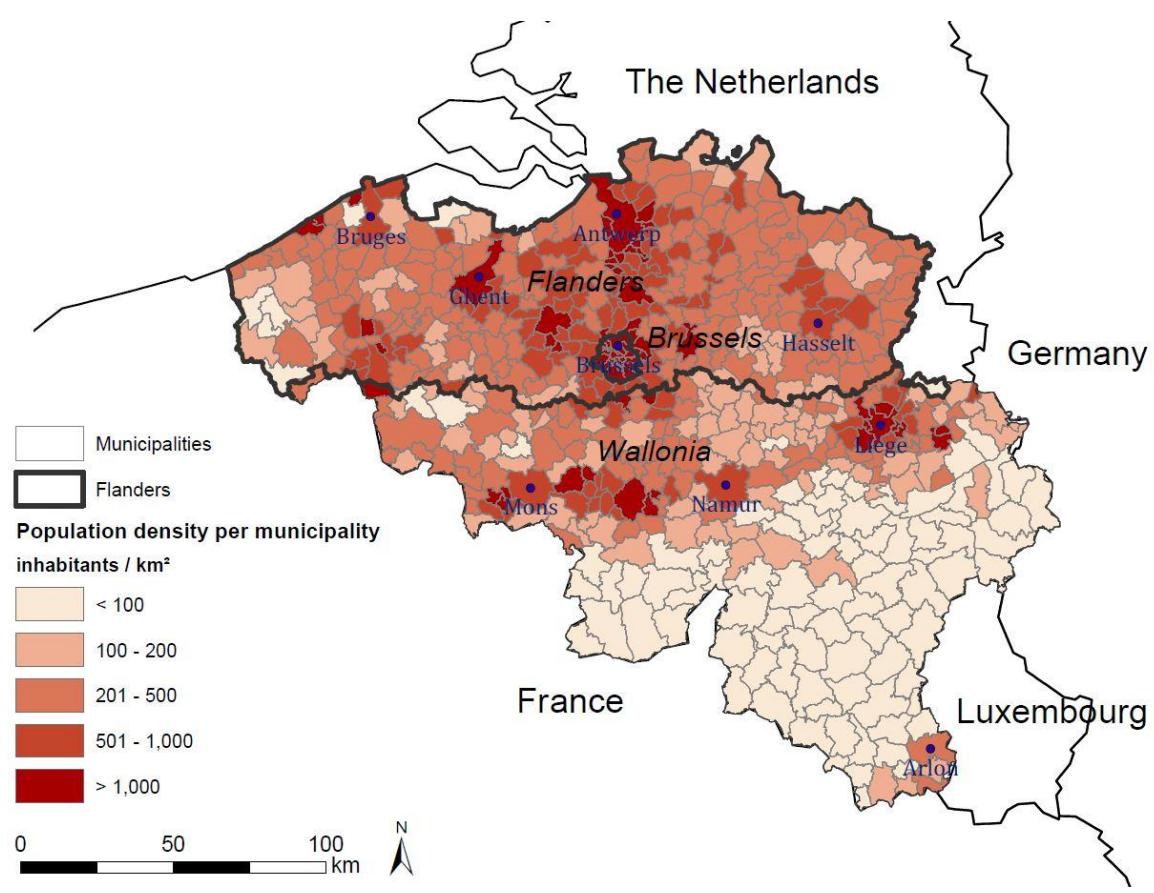

Fig. 1: Study area. specifying Belgium and its neighboring countries, the location of Flanders, Brussels and Wallonia, and the population density per municipality

Data

Three sources of data were used to measure public transport gaps in Flanders. First, the population size segmented by socio-demographic variables of the year 2013 was applied. These variable are either available per traffic analysis zone (TAZ) or at the municipality level. The categories of exclusion in transport are diverse, ranging from physical and spatial to socioeconomic factors. Based on previous studies (Currie, 2010; Jaramillo et al., 2012; Kamruzzaman and Hine, 2011) and in consultation with experts from De Lijn, the most relevant information about the relative size of those socio-demographic groups that tend to depend largely on public transportation was chosen. These groups are depicted in Figure 2 and include:

- percentage of the population aged 65 years and older (Fig. 2a);

- percentage of the population aged 6 to 11 years (Fig. 2b);

- percentage of households without privately owned motorized vehicle (Fig. 2c);

- percentage of the active population that is unemployed (Fig. 2d).

In addition, Fig. 2e depicts the percentage of the population receiving subsistence per municipality and acts as an indicator for an inhabitant's socio-economic situation. This information was made available by the Provincial Public Service Social Integration (Provinciale Overheidsdienst Maatschappelijke Integratie) and was aggregated on the municipality level due to unavailability per TAZ. According to Fig. 2, the age-related variables (percentage of the population aged 65 years and older and 6 to 11 years) and the variable related to carownership exhibit spatially random distributions, while the variables related to unemployment and subsistence are mainly characterized by a clustered pattern. This clustered distribution facilitates transit agencies to close public transport gaps, as localized service improvements can benefit a large amount of inhabitants. However, failing to provide sufficient service in clusters leads to a higher possibility of underserving large numbers of inhabitants at risk. 
a)

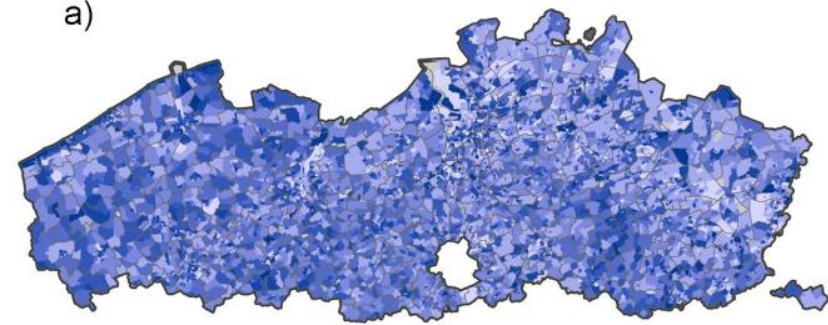

$\%$ over 65

$<9.00$

$9.00-15.00$

$15.00-17.00$

c)

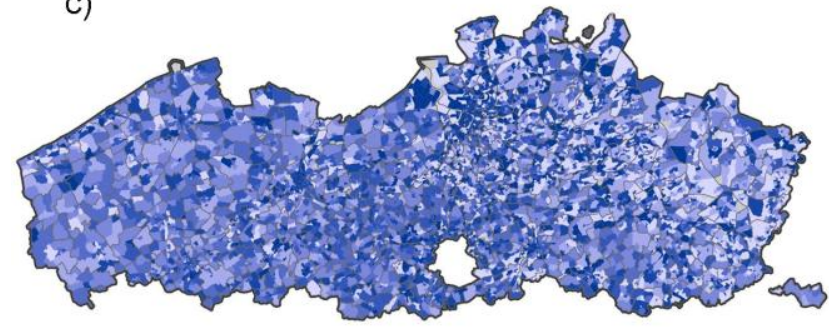

$\%$ households without a car

$<6.50$

$6.50-14.00$

$14.00-17.00$

e)

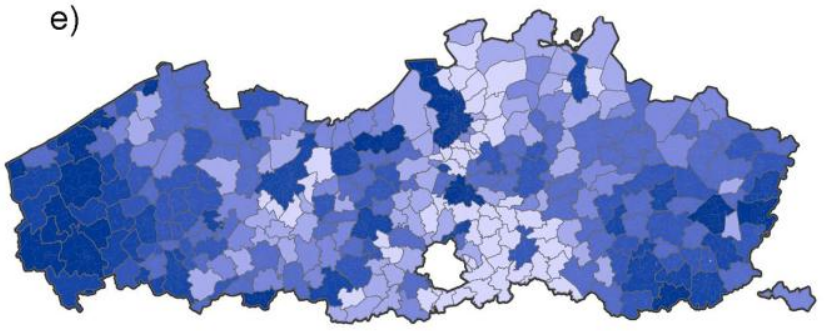

$\%$ receiving subsistence

$<9.00$

$9.00-11.00$

$11.00-12.00$

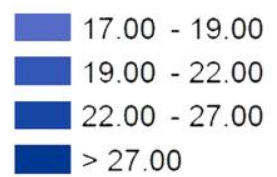

27.00

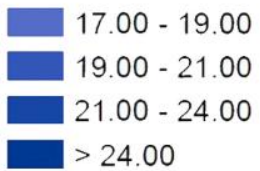

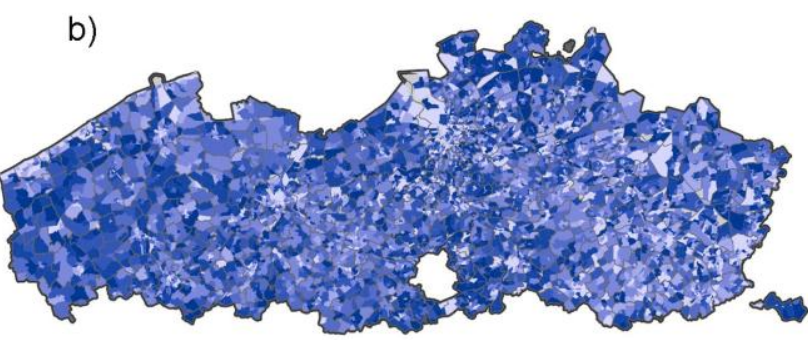

$\% 6-11$ years

$<4.50$

$4.50-5.50$

$5.50-6.50$

d)

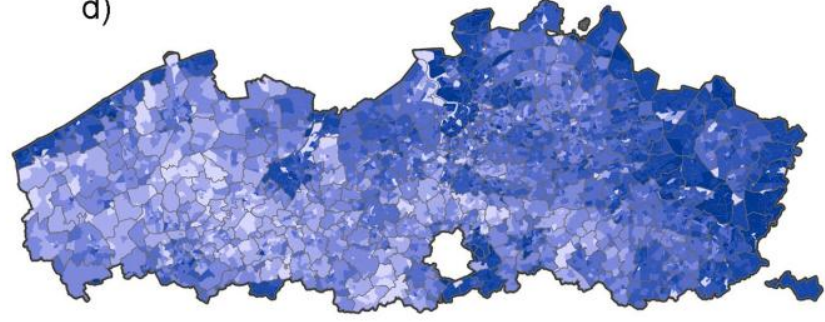

$\%$ unemployed

$<25.00$

$25.00-27.50$

$27.50-30.00$
$6.50-7.00$

$7.00-7.50$

$7.50-8.50$

$>8.50$

$30.00-32.50$

$32.50-35.00$

$35.00-40.00$

$>40.00$

Fig. 2: Population aged 65 years and older (a), children aged between 6 and 12 (b), households without a car (c) and unemployed population (d) per PTAZ and population receiving subsistence allocation (e) per municipality in Flanders, quantile classification

A second group of data includes facility locations. Various types of indicators were geocoded at the address level and, when appropriate, opportunity constraints were aggregated at the TAZ level. These opportunities refer to the number of jobs and the student capacity available at each location. These, in combination with the data required to estimate travel times, were used to model the provision of facilities. The maps in Fig. 3 depict their spatial distribution. The study area is well covered with stronger concentration in the city centers. The addresses of the following active facilities in Belgium were implemented:

- 34,494 physicians, MDs, and other medical practitioners (Fig. 3a);

- 198 hospitals (Fig. 3a);

- 603 administrative centers (Fig. 3b); 
The data was compiled from various sources. The dataset containing the locations of all medical practitioners in Belgium was provided by the National Institute for Disease and Invalidity Insurance (RIZIV), while those consisting of the hospitals, the administrative centers and the supermarkets were derived from the TomTom MultiNet version 2013.03. Furthermore, the addresses of all active day-care centers for the Flemish speaking community for children aged two years and younger were geocoded. The day-care center data was made available by the Flemish agency for Child and Family. The number of jobs (Fig. 3e) and the capacity in education (Fig. 3f) was provided by the public transport company De Lijn. Brussels was included in the job dataset due to the strong concentration of jobs in this area. Because both day-care centers and education are regionalized competences, this data was only incorporated for the Dutch-speaking region of Flanders. The variables were selected due to their availability on the address level and represent a cross section of primary needs that are considered crucial to improve an inhabitant's quality of life (health care, services, sustenance, education and employment). Therefore, the applied facility types have a universal and essential character and arguably make up a 'normal' range of opportunities that should be adequately accessible for all citizens in a society. Spatial autocorrelation indicates that all variables have a significantly clustered pattern $(z$-score $>1.96, p$-value $<0.05)$. This clustering is strongly related to the location of the major city centers. When available, data about facilities located in Wallonia and/or Brussels are included in the analysis to alleviate edge effects. This means that individuals are assumed to be prepared to visit these facilities outside Flanders. However, a language barrier exists, and it is unknown to what extent this barrier affects the propensity to participate in cross-border activities.

a)

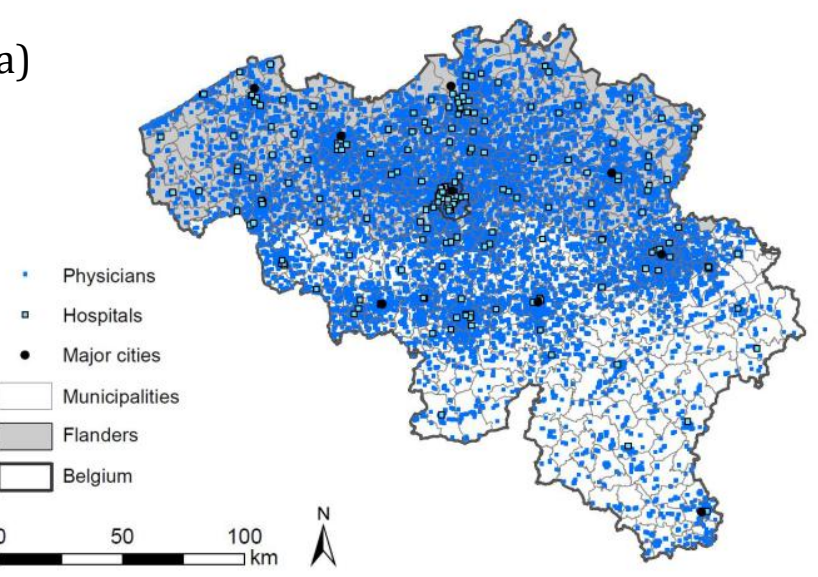

b)

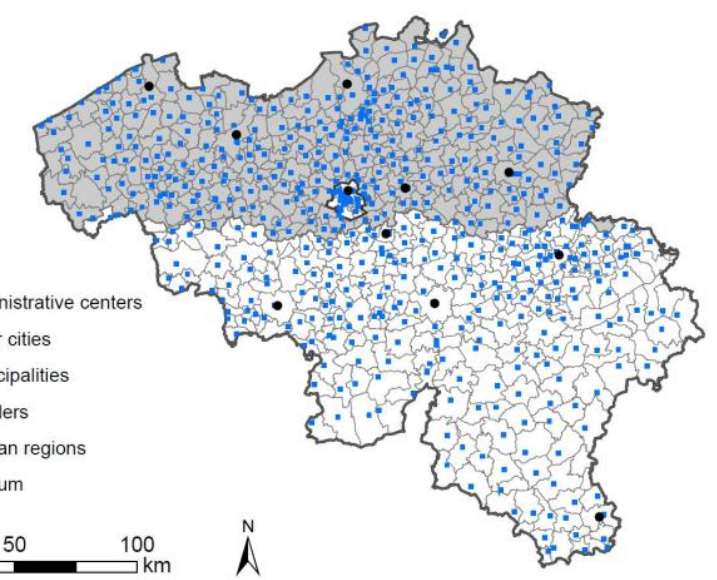



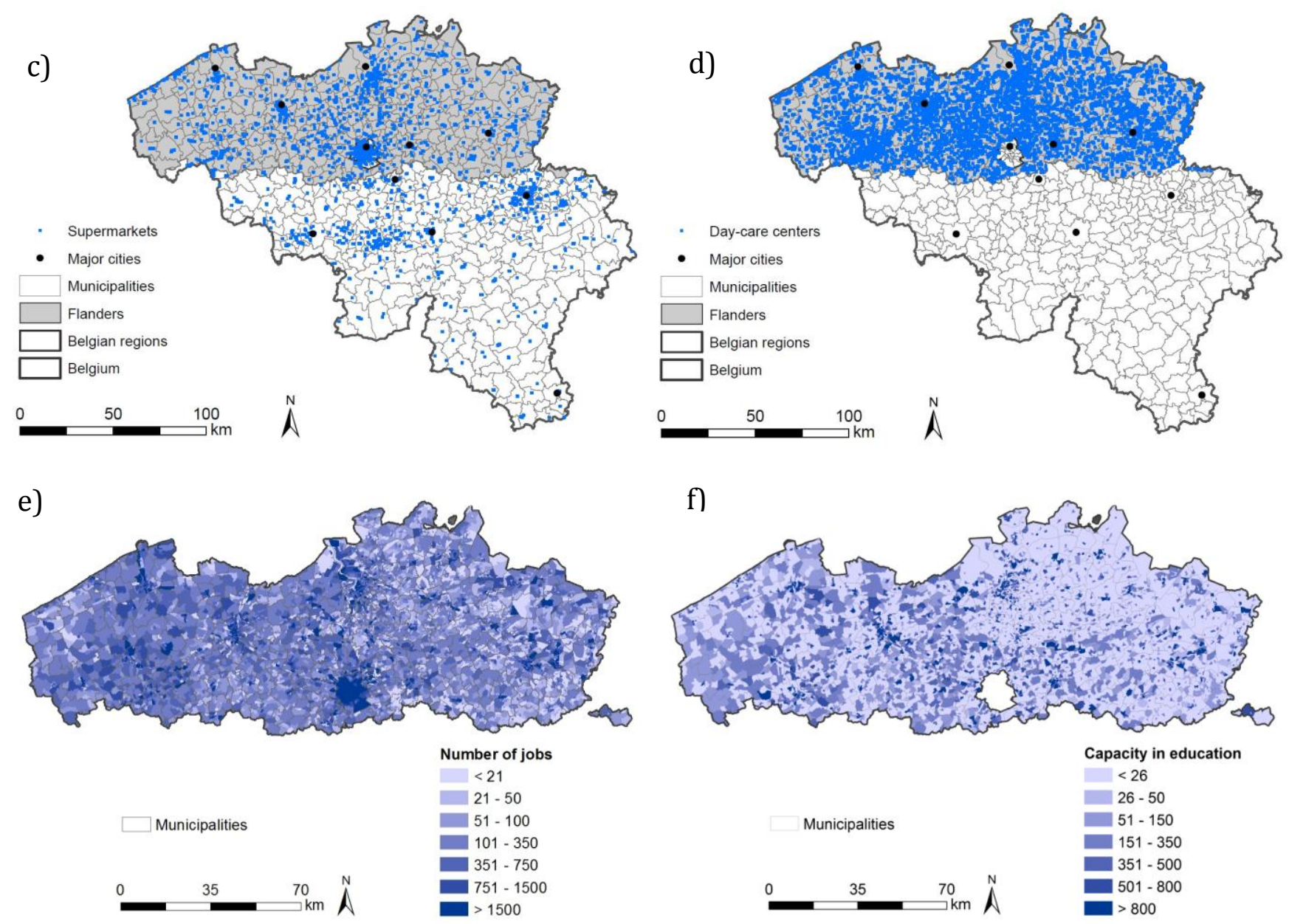

Fig. 3: Spatial distribution of healthcare facilities (a), administrative centers (b), supermarkets (c) and day-care centers (d) in Belgium and number of jobs (e) and capacity in education (f) in Flanders per TAZ

The third group of data comprises the transport network data. Analogous to Farber et al. (2014), a routable network was created using the Add GTFS to a Network Dataset tools developed by Esri's Network Analyst Team. This tool enables integrating GTFS datasets for bus, tram, metro and train as well as street network data into a single multimodal network that accounts for the following components of a public transport trip: the walking time from the origin to the public transport stop through the pedestrian network (ingress), the waiting time at the public transport stop (including the time to enter or exit the vehicle), the actual travel time through the transit network (including transfers) using timetable information and the walking time from the public transport stop to the destination through the pedestrian network (egress). Incorporating the network into a Python script made it possible to iterate different functionalities (e.g. calculation of origin-destinations matrices and service area analyses) over various times of the day. Pedestrian travel for pre- and post-transit was estimated using the TomTom MultiNet version 2013.03, which contains a comprehensive topological representation of the Belgian road network. A walking speed of $4 \mathrm{~km} / \mathrm{h}$ was assumed, which corresponds to an adult's average walking speed (Ritsema van Eck et al., 2005). This value is a modifiable network variable that could be used to represent travel speeds for different aged people or users of various ingress and egress modes (e.g. bicycles or motor vehicles). A built-in restriction excluded major motorways, highways and highway ramps from the network, since these are not accessible to pedestrians. The transit network dataset was constructed from the transit stops, routes and schedules specified in the GTFS datasets provided by various public transport companies: Nationale Maatschappij der Belgische Spoorwegen (NMBS) for transit by train in Belgium, De Lijn for transit by bus and tram in Flanders, Transport en Commune (TEC) for transit by bus and tram in Wallonia, and Maatschappij voor het Intercommunaal Vervoer in Brussel (MIVB) for bus, tram and metro in Brussels. Defining the connectivity of intersections 
of the transit and pedestrian network constrained users to transition solely between these networks at public transport stops. Also, a delay of 0.25 min was assumed for transitions between streets and transit lines to represent boarding and alighting.

\section{Methodology}

In line with Currie (2010) and Jaramillo et al. (2012), this study aims to detect public transport gaps in Flanders by comparing public transport needs and provision. To that end, an Index of Public Transport Needs (IPTN) and an Index of Public Transport Provision (IPTP) were constructed.

\section{Index of Public Transport Needs (IPTN)}

The spatial distribution of socio-demographics groups (Section 3) was used to determine a general index for public transport needs. The construction of the index as proposed by Currie (2010) was taken as a basis, and the applied variables and their weightings were adapted to better suit the context at hand. In addition to variables such as age or social status, proximity to diverse primary facilities plays an important role in determining the need for public transportation. If a person has neither a car nor the financial resources to buy one, but nonetheless lives in the proximity (walking or biking distance) of primary facilities such as jobs or healthcare, then (s)he is not considered dependent on public transport. For this reason, the number of primary facilities available within walking or biking distance was included as a variable in the calculation of the public transport needs. ArcGIS was applied to calculate the distance from each TAZ centroid to the closest facilities. If this distance measured less than 1.0 or 2.5 kilometers, the facility was considered available on foot or by bicycle, respectively. These distances correspond with an average travel time of 15 minutes, which is the maximum travel time standard in Europe aimed at for more than $90 \%$ of the population (Doerner et al., 2007).

To derive an index of public transport needs for each TAZ, a statistical approach based on factor analysis was employed. Generally, factor analysis is used to perform a dimension reduction on data: a high number of variables is reduced to a smaller group of uncorrelated components (Jaramillo et al., 2012). Here, analogous to similar studies on transport disadvantage (Jaramillo et al., 2012; Kamruzzaman and Hine, 2011), the components were used to eventually calculate a single index per zone. The resulting IPTN is based on the correlation between the variables and accounts for a large part of the variance between the zones. Those variables that contain the largest variation across different areas are assigned the highest weights. Consequently, factor analysis reveals the underlying structure of the data based on the variables' high correlation.

Principal component analysis was used as the extraction method (Table 1). Three components with a strong correlation with the first principal component were selected by applying the latent root criteria for the number of components, indicating characteristic values (eigenvalues) larger than 1.000 . These components individually explained more than $10 \%$ and cumulatively more than $55 \%$ of the total variance of the data. Subsequently, the three extracted components were rotated using the Varimax Rotation method ${ }^{2}$ with Kaiser normalization ${ }^{3}$, with a rotation converging in four iterations (Table 2). The factor loadings indicated that the first component had high loadings on the number of primary facilities within walking (0.864) and biking distance $(0.890)$, hence representing the proximity to primary functions. The second component was strongly associated with the percentage of the population aged 65 or older $(0.675)$, the

\footnotetext{
${ }^{2}$ Rotation further analyzes initial principal component analysis and aims to make the pattern of loadings more pronounced by arranging the components as much apart from each other as possible.

${ }^{3}$ Kaiser normalization normalizes the factor loadings before rotating them and, subsequently, denormalizes them after rotation.
} 
percentage of the population that is unemployed (0.675) and the percentage of families without a car (0.659), which represent the inability to own and/or use a car. The third component had a high negative factor loading for subsistence allocation $(-0.745)$ and a high positive factor loading for children (0.731). None of the variables had high loadings on more than one component (higher than 0.300 ). Therefore, no complex structures on extracted components occurred. Each component was weighted by its relative influence (normalized to unity) on the overall variance. Finally, an IPTN per TAZ was calculated by applying a linear combination of the factor loadings as weights for the individual variables. TAZs with a high index are considered to be relatively disadvantaged.

Table 1: Extraction of principal components from the individual variables for the Initial Solution and the Varimax Rotation method

\begin{tabular}{lrrrrr}
\hline \multirow{2}{*}{ Component } & \multicolumn{2}{l}{ Initial Eigenvalues } & \multicolumn{3}{c}{ Rotation Sums of Squared Loadings } \\
\cline { 2 - 6 } & Total & $\begin{array}{r}\text { Variance } \\
\text { explained }\end{array}$ & Total & $\begin{array}{r}\text { Variance } \\
\text { explained }\end{array}$ & $\begin{array}{r}\text { Cumulative } \\
\text { variance }\end{array}$ \\
\cline { 2 - 6 } 1 & 1.635 & 23.362 & 1.545 & 22.071 & 22.071 \\
2 & 1.338 & 19.120 & 1.374 & 19.626 & 41.697 \\
3 & 1.073 & 15.323 & 1.128 & 16.108 & 57.805 \\
4 & 0.886 & 12.655 & & & \\
5 & 0.830 & 11.857 & & & \\
6 & 0.803 & 11.464 & & & \\
7 & 0.435 & 6.218 & & & \\
\hline
\end{tabular}

Table 2: Rotated component matrix (Varimax Rotation) showing the factor loadings for each variable-component pair

\begin{tabular}{llll}
\hline \multirow{2}{*}{ Variable } & \multicolumn{3}{c}{ Component } \\
\cline { 2 - 4 } & 1 & 2 & 3 \\
\hline Walking distance & 0.864 & -0.060 & 0.150 \\
Biking distance & 0.890 & 0.001 & -0.045 \\
Elderly & -0.002 & 0.675 & -0.008 \\
Unemployed population & -0.013 & 0.675 & -0.099 \\
Car ownership & -0.043 & 0.659 & 0.058 \\
Subsistence allocation & -0.017 & 0.131 & -0.745 \\
Children & 0.067 & 0.089 & 0.731 \\
\hline
\end{tabular}

Index of Public Transport Provision (IPTP)

A spatio-temporal accessibility metric was constructed to represent the provision of the public transport network to various primary facilities for each TAZ. Transit trips through the public transport network were computed at specific times of the day and consequently represented the optimal path through the network at that particular time.

First, origin-destination cost matrices (ODCM) between the TAZ centroids were calculated in ESRI ArcGIS. A cut-off travel time of 60 minutes was appointed to reduce computation time. This process was iterated every five minutes, over a time period of three hours (6 to 9am for peak hours and 11 am to $2 \mathrm{pm}$ for off-peak hours).

In a second step, these travel times were used to determine the number of accessible opportunities for several time intervals for each TAZ. If the travel time between an origindestination pair calculated in the first step was located within a predefined travel time interval (in this study ranging from 0 to 60 minutes with intervals every 10 minutes), the number of 
facilities (or the number of jobs or educational opportunities)at the destination zone were summarized:

$$
A_{i, S, T}=\sum_{j} G\left(t_{i j}\right) F_{S, j}
$$

where $A_{i, S, T}$ is the accessibility index for location $i$, for a service type $S$ and time threshold $T . t_{i, j}$ indicates the travel time between origin $i$ and destination $j, G\left(t_{i j}\right)$ is an indicator function equal to 1 if $t_{i j} \leq T$ and $T \in\left(0-10,10-20,20-30,30-40,40-50\right.$ or 50 - 60 minutes). Finally, $F_{S, j}$ denotes the opportunities of facility type $S$ at location $j$. As such, a number of accessible opportunities was determined per time threshold for each service type separately (the number of students, jobs, hospitals, supermarkets, administrative centers, physicians and day-care places). This process was iterated over the same temporal cross-sections as in the first step. In a third step the accessible facilities per service type and time interval were combined into accessibility single index per TAZ. An average accessibility index was calculated by averaging values for the different time thresholds, applying higher weights for facilities closer to the origin zone:

$$
A_{i, S}=\sum_{T=1}^{n} A_{i, S, T} W_{T}
$$

where $A_{i, S}$ is the accessibility index for a certain service type $S, n$ corresponds with the number of travel time intervals, $A_{i, S, T}$ is the accessibility index for a certain service type $S$ at a certain time threshold $T$, and $W_{T}$ equals the weight corresponding with a certain time interval $T$ (in this study linearly: 6/6, 5/6, 4/6, 3/6, 2/6, 1/6 for time intervals 0 - 10, 10 - 20, 20 - 30, 30 - 40, 40 50 and 50 - 60 minutes respectively). This impedance function is similar to that applied by Schuurman et al. (2010) and Henry et al. (2013). Finally, an IPTP was calculated by normalizing the indices per service type to unity and calculating the average accessibility to primary facilities. TAZs with a high index are considered to have a relatively high provision of facilities. The calculation was performed for peak hours on an average weekday (Tuesday from 6 till 9 AM), off-peak hours on an average weekday (Tuesday from 11 AM till 2 PM) and offpeak hours in the weekend (Saturday and Sunday from 11 AM till 2 PM).

Index of Public Transport Gaps (IPTG)

The Index of Public Transport Gaps (IPTG) was computed as the difference between public transport needs and provision:

$$
\text { IPTG = IPTN - IPTP }
$$

Both the IPTN and the IPTP were normalized in order to make the indices commensurable. The resulting IPTG allows comparison between the different TAZs in order to delineate the differences in transport gaps within and between zones in the study area. On the one hand, higher values of this index designate areas that need considerable attention in public transport planning due to an overall high need for and underprovision of public transportation. On the other hand, lower IPTG are significant for De Lijn (and other public transport companies) from an economic point of view as they indicate areas with a provision exceeding the need. Consequently, service in these areas can be constricted, which leads to financial benefits. 


\section{Results}

\section{Public transport needs and provision}

Fig. 4 represents the IPTN for Flanders. TAZs with a relatively high index denote areas that are transport disadvantaged and in need of a strong provision. TAZs in the rural and suburban parts of Flanders are mainly characterized by a high IPTN, due to their specific sociodemographics and lower access to primary facilities. Relatively low IPTN are found for the urban (e.g. city center of Ghent or Antwerp) and coastal areas, mainly due to the higher number of primary functions within walking or biking distance. When the geography of IPTN is compared to the population density, the highest indices are found in the less populated areas (e.g. urban harbors of Ghent or Antwerp or rural and more peripheral areas, Fig. 5) and the lower indices in the densely populated city centers. As a result, most inhabitants reside in an area not characterized as public transport dependent. An indication of the number of inhabitants dependent on public transport allows De Lijn to either determine improvements to make the public transport network more accessible in areas with higher numbers (higher frequency, more stops, etc.) or to provide alternative programs in areas with lower numbers in order to rationalize the current network (smaller taxi buses, replacement subsidies, etc.). In addition, TAZs bordering the Netherlands (north of Flanders) or France (southwest of Flanders) also exhibit high levels of IPTN. Possible border effects could occur at the study area's borders due to the absence of public transport data for cross-border travel to the neighboring countries. Because public transport in Wallonia and Brussels is taken into account, border-related limitations are not apparent for areas adjacent to these regions.

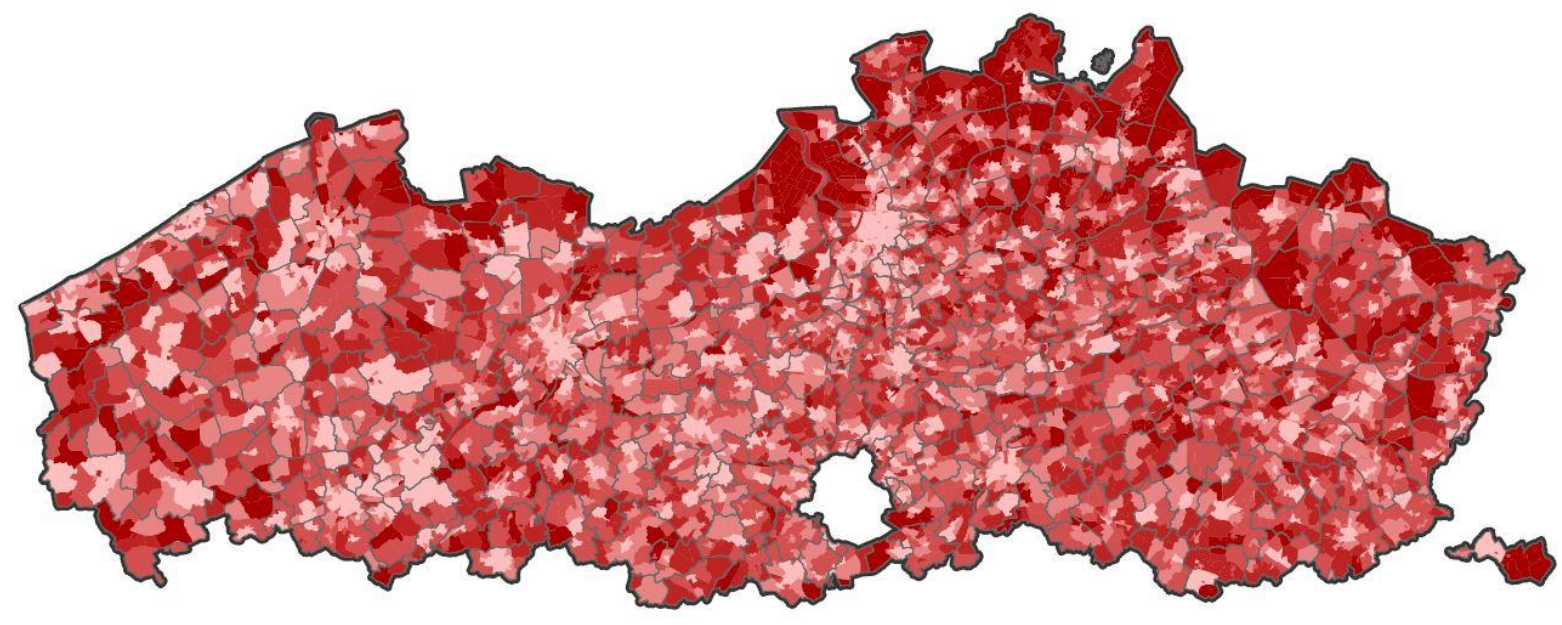

Municipalities

Index of Public Transport Needs

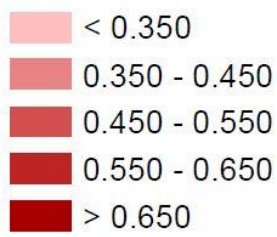

Fig. 4: Indices of Public Transport Needs per TAZ 


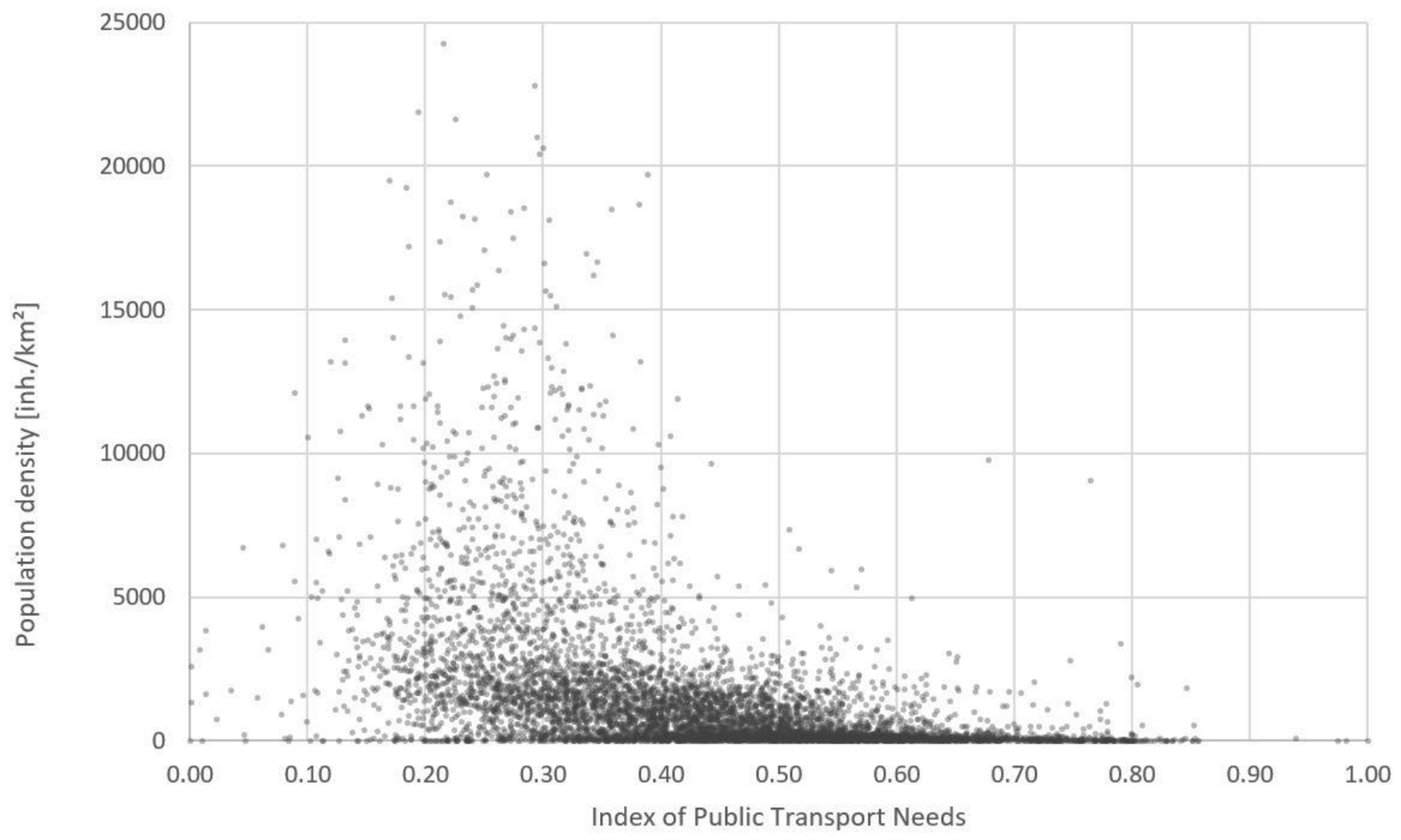

Fig. 5: The Index of Public Transport Needs in relation to the population density per TAZ

Fig. 6 a shows the IPTP during morning peak hours (6 till 9 AM) on an average weekday. A high provision of primary facilities through public transport is noted in cities, due to the high proximity of facilities and availability of public transit. Analysis for various times of the week indicates a strong decline of provision by public transport for off-peak travel times, especially for suburban areas. Fig. 6b shows the IPTP during off-peak hours (11 AM till 14 PM) on a Sunday. The indices remain high in urban areas and along the railway tracks running peripherally from the larger cities. Especially Brussels and its surroundings are characterized by high indices, primarily due to the high frequency of railway to and from the city. In suburban and rural areas however, the indices are noticeably lower, which correlates with the lower transit frequencies during off-peak hours and in the weekends. 
a)

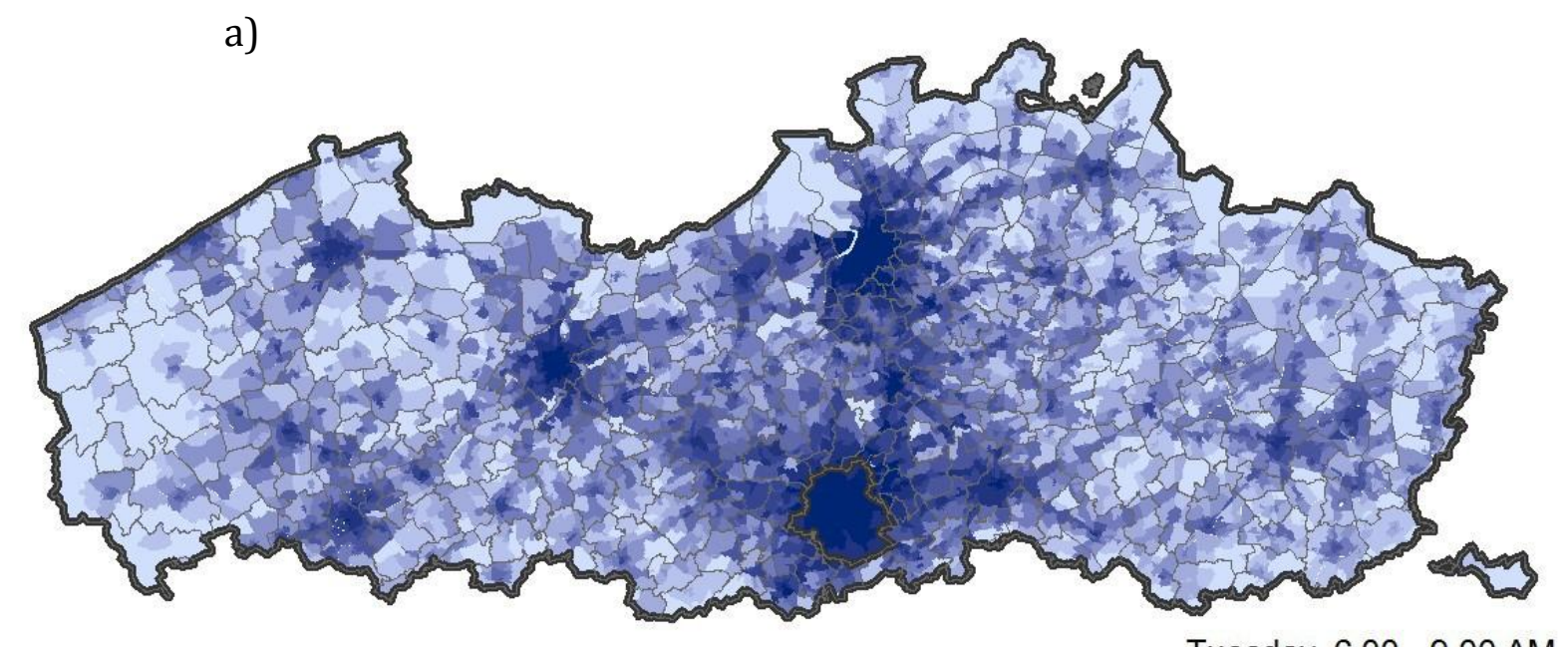

b)

Tuesday, 6.00 - 9.00 AM

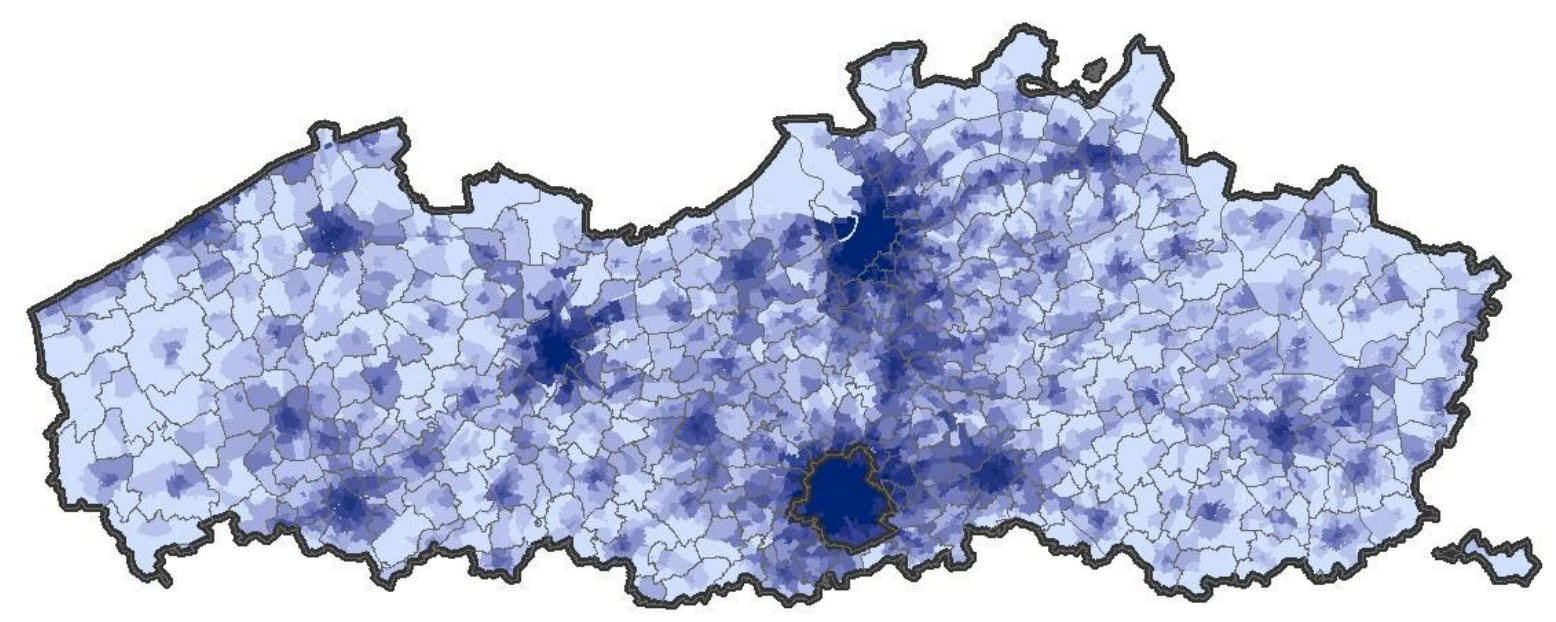

Sunday, 11.00 AM - 2.00 PM

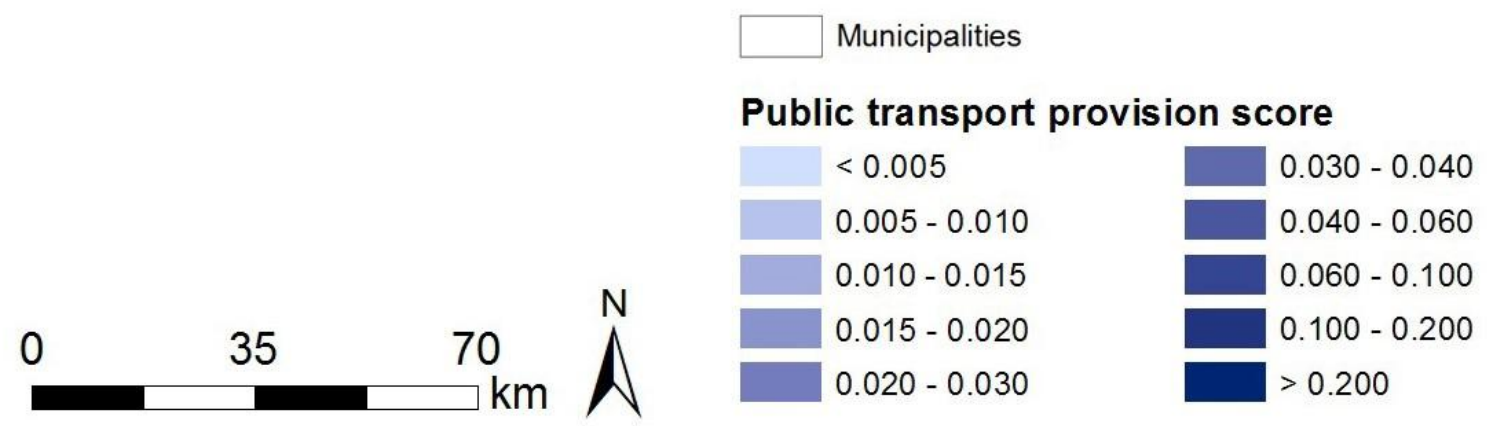

Fig. 6: Public transport provision indices per TAZ for Flanders and Brussels, for various times of the week

As mentioned, the IPTP varies between different temporal sections because of the strong temporal variability related to public transport. For example, on average $11 \%$ less jobs are accessible during off-peak hours than during peak hours. In addition, this index fluctuates in the considered time windows. Between 6.30 and $7 \mathrm{AM}$, the average number of accessible jobs peaks, which corresponds with the time of day that major commuting flows occur. After 7 AM, this number drops as less people commute. During off-peak hours, the temporal variability is rather cyclic and corresponds to periods of higher provision every 30 minutes (Fig. 7). These results indicate that the current provision of public transport is adapted to the traditional daily rhythm of life. Moreover, they provide important information for transport companies to better align their services to these specific everyday patterns. 


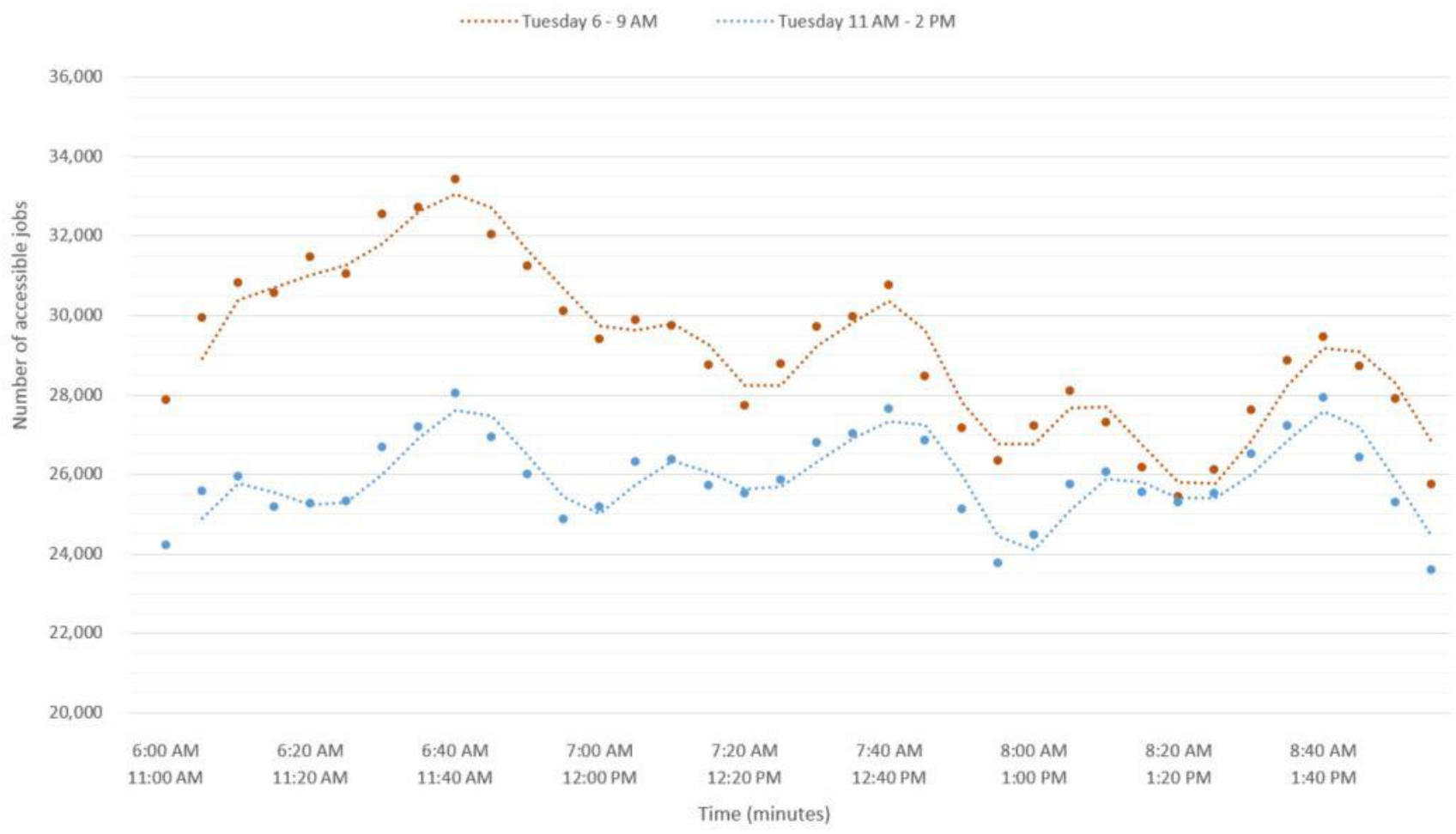

Fig. 7: Temporal fluctuations in the access to jobs during peak (6 to 9 AM) and off-peak (11 AM to 2 PM) hours on an average Tuesday

\section{Public transport gaps}

The IPTN and IPTP per zone are compared in order to define areas characterized by public transport gaps. Fig. 8 shows the deciles of lowest and highest public transport disparities in Flanders for an average weekday during peak hours. Lower indices are mainly found in urban areas while suburban and peripheral areas are generally characterized by higher gap values. The areas with lower disparities have a public transport provision in correspondence to or exceeding its need and mainly coincide with urban centers, while those with higher disparities pinpoint areas with a mismatch between the need and provision and are primarily located suburban or rural. 

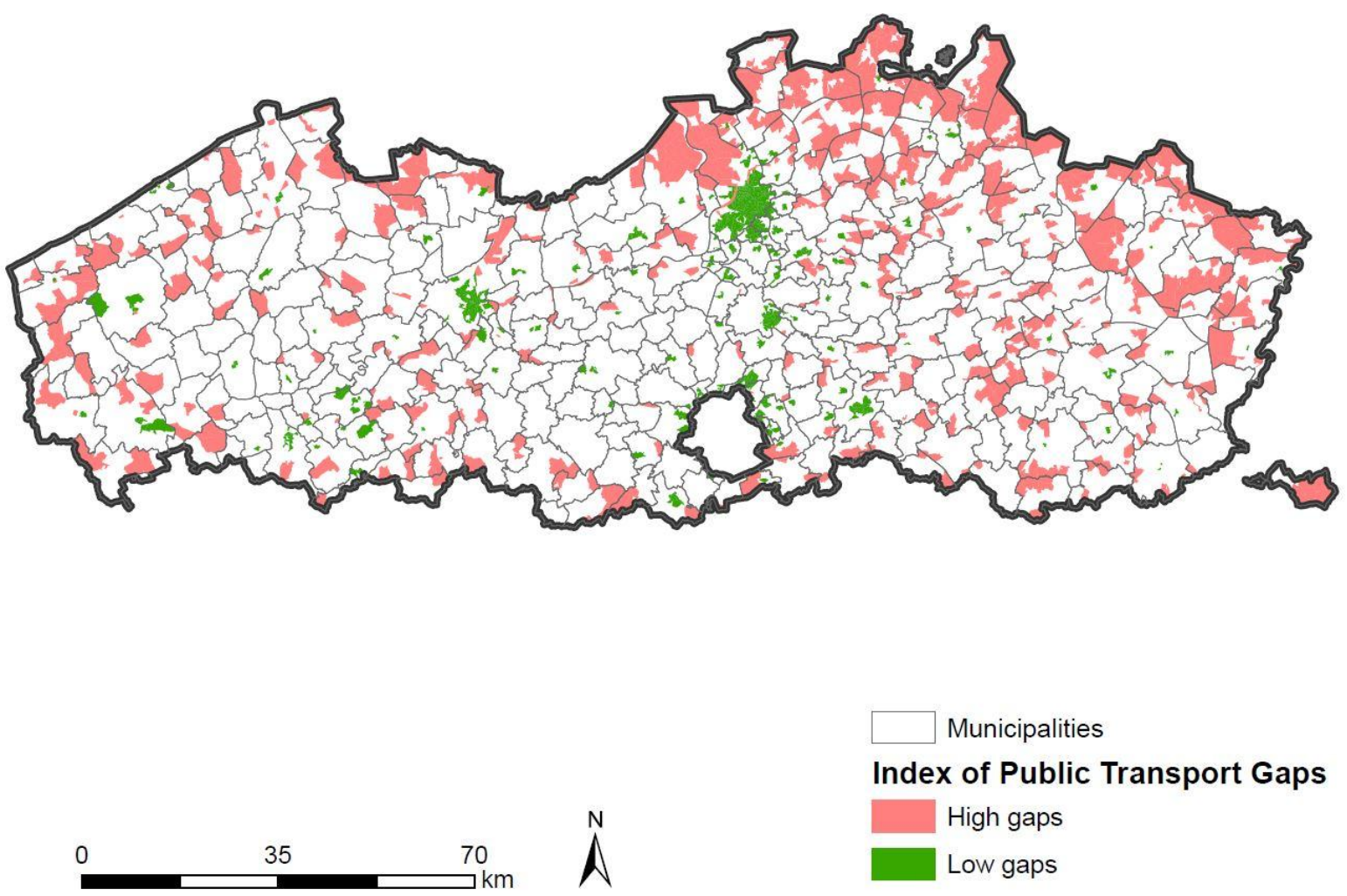

Fig. 8: Public transport gap index per TAZ for Flanders

Table 3 shows that the lowest decile spans an area of more than $2500 \mathrm{~km}^{2}$ with an average of close to $4 \mathrm{~km}^{2}$ per zone and is characterized by a low population density. This is in contrast with the highest decile, which contains overall smaller zones with an average area of $0.44 \mathrm{~km}^{2}$ and a higher population density. In addition, Table 4 shows the IPTN, IPTP and IPTG for various time windows of the week for both deciles. The variances, means, minima and maxima indicate the internal variance of each decile consisting of multiple TAZs. The values in the highest decile are characterized by a high mean IPTG and high variances. The lowest decile values have a low mean IPTG with little variation between the TAZs they comprise.

Table 3: Descriptives for the deciles with highest and lowest values

\begin{tabular}{lrrrrr}
\hline & $\mathrm{N}$ & Total area $\left(\mathrm{km}^{2}\right)$ & Average area $\left(\mathrm{km}^{2}\right)$ & Total population & Average population \\
\cline { 2 - 6 } Low gaps & 654 & 288.43 & 0.44 & 1099531.17 & 1681.24 \\
High gaps & 654 & 2587.11 & 3.96 & 242685.60 & 371.08 \\
\hline
\end{tabular}

Table 4: IPTN, IPTP and IPTG for the high-high and low-low clusters

\begin{tabular}{|c|c|c|c|c|c|c|c|c|c|c|}
\hline & & \multirow[t]{3}{*}{ IPTN } & \multicolumn{4}{|c|}{ IPTP } & \multicolumn{4}{|c|}{ IPTG } \\
\hline & & & Tuesday & Tuesday & Saturday & Sunday & Tuesday & Tuesday & Saturday & Sunday \\
\hline & & & $6-9$ AM & $11 \mathrm{AM}-2 \mathrm{PM}$ & $11 \mathrm{AM}-2 \mathrm{PM}$ & $11 \mathrm{AM}-2 \mathrm{PM}$ & $6-9 \mathrm{AM}$ & $11 \mathrm{AM}-2 \mathrm{PM}$ & 11 AM - 2 PM & $11 \mathrm{AM}-2 \mathrm{PM}$ \\
\hline \multicolumn{11}{|l|}{ Low gaps } \\
\hline & Aver. & 0.2403 & 0.2295 & 0.2155 & 0.2113 & 0.1999 & -0.0109 & -0.0248 & -0.0290 & -0.0404 \\
\hline & Min. & 0.0000 & 0.0051 & 0.0062 & 0.0076 & 0.0064 & -0.1298 & -0.2016 & -0.2767 & -0.2836 \\
\hline & Max. & 0.4577 & 0.6337 & 0.6215 & 0.5722 & 0.5682 & 0.4701 & 0.4546 & 0.4798 & 0.4723 \\
\hline & Std. dev. & 0.0786 & 0.1198 & 0.1204 & 0.1347 & 0.1317 & 0.1081 & 0.1105 & 0.1230 & 0.1217 \\
\hline \multicolumn{11}{|l|}{ High gaps } \\
\hline & Aver. & 0.6981 & 0.0107 & 0.0083 & 0.0083 & 0.0072 & -0.6875 & -0.6898 & -0.6898 & -0.6909 \\
\hline & Min. & 0.6067 & 0.0000 & 0.0000 & 0.0000 & 0.0000 & -0.9990 & -0.9991 & -0.9991 & -0.9990 \\
\hline & Max. & 1.0000 & 0.1624 & 0.1654 & 0.1923 & 0.1718 & -0.6062 & -0.6005 & -0.5849 & -0.6042 \\
\hline & Std. dev. & 0.0646 & 0.0160 & 0.0139 & 0.0143 & 0.0125 & 0.0662 & 0.0656 & 0.0657 & 0.0653 \\
\hline
\end{tabular}


While the focus of the paper thus far has been on a generalized IPTG, the measures produced in this analysis also allow to investigate specific transit gaps for a certain type of need in respect to the appropriately related type of provision. In order to demonstrate this, the specific need for inhabitants aged 65 years and older is compared to the provision of physicians. Fig. 9 denotes a more scattered pattern for the high gaps, with stronger concentrations of gaps in the western part. The highest values are found in the urban centers, with a stronger representation around Brussels. These types of specific comparisons can be made by transit agencies, policy makers or academics in pursuit of answers to more focused research questions.

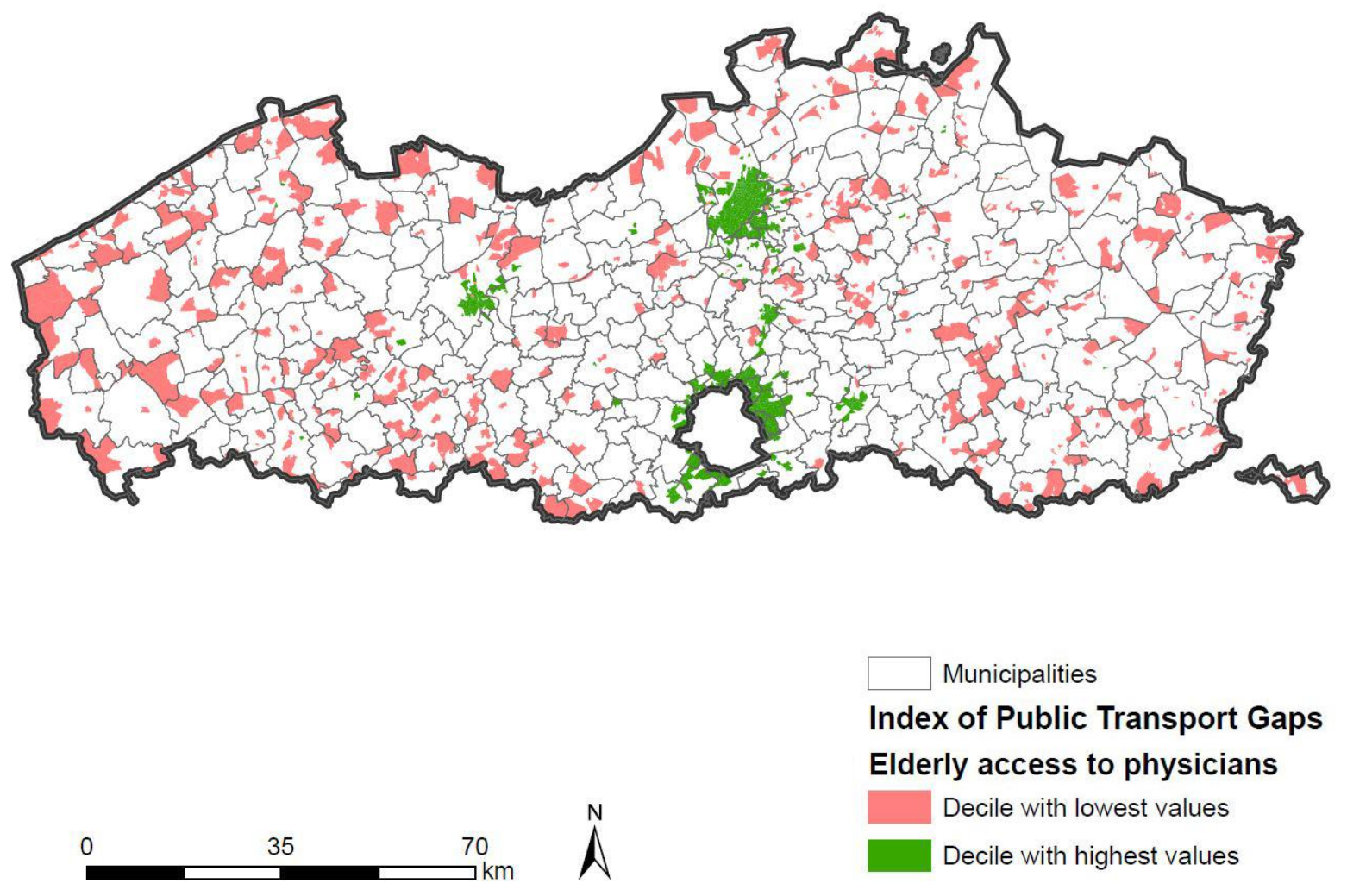

Fig. 9: Public transport gap index for elderly access to physicians per TAZ for Flanders

\section{Conclusion and discussion}

This article has proposed a methodology to identify transport gaps in Flanders, Belgium. While previous studies generally do not consider the temporal variability in accessibility levels at multiple origins, this study shows the importance of modeling time-continuous, schedule-based public transport accessibility to identify public transport gaps. To that end, an index of public transport needs (IPTN) and one for its provision (IPTP) was developed.

The IPTN accounted for multiple socio-demographic variables as well as spatial conditions of proximity. Several variables were weighted and applied to derive a general index of public transport needs. This index was based on the travel time through public transport to various primary facilities and was calculated over various peak and off-peak time windows for different times of the week. A higher IPTN indicated areas that strongly rely on public transport for daily transportation (e.g. rural areas), while lower indices pinpointed areas with lower needs (e.g. city centers). Although inhabitants of rural municipalities often choose a certain way of life related to a strong dependency on private means of transportation, policy tends to provide public transport for every inhabitant for multiple reasons such as environmental or social costs.

When high IPTN are accompanied by high IPTP, the provision meets the needs. However, important policy measures can be taken for areas characterized by a mismatch between both 
indices. Areas with low IPTN and high IPTP are an indicator for policies aimed at reducing the current public transport provision while those with high IPTN and low IPTP denote areas where public transport provision should be reinforced or substituted by alternative actions. The method proved to be effective for comparing different areas as well as the accessibility effects of changes in the public transport network. Additionally, the high degree of time variability within one specific time frame suggested the inadequacy of applying a single temporal section for transit-based accessibility research. However, this temporal variability was less apparent at the aggregate level of analysis, as the time of day did not strongly affect the transport gaps pattern.

While this paper represents a significant improvement of prior work in this area, at least five areas for future work can be identified. First, methodology should incorporate cross-border public transport data in the analysis. In the northern part of Flanders bordering the Netherlands, mainly low IPTG were found. However, a number of inhabitants living in these areas make use of primary facilities located outside of Flanders. Information concerning crossborder public transport as well as the location of primary facilities was not available. Therefore, indices in these area are underestimated and, relative to other analyzed TAZs, less reliable. Although data on primary facilities was also missing for day-care centers in the region of Brussels and Wallonia (both also bordering Flanders), the availability of public transport data as well as the locations of all other primary facilities was sufficient to derive a well substantiated IPTG. Nonetheless, indices in these areas are slightly underestimated.

A second improvement can be obtained by augmenting the level of detail of the subsistence allocation data. Because a variable for socio-economic stratum was not at hand on the level of TAZs, in contrast to the other variables, data on the municipality level was applied in determining the IPTN. However, the socio-economic stratum is crucial in defining public transport needs (Jaramillo et al., 2012; Kamruzzaman and Hine, 2011). To this end, more detailed information concerning this variable is necessary for future studies on the subject.

Third, while the calculation of public transport provision considered time variability, the method for defining public transport needs did not. Transport disadvantage also varies over time, because not all groups are disadvantaged all the time (Kamruzzaman and Hine, 2011; Wu and Hine, 2003). For example, public transport policy measures for unemployed should focus on weekday transportation in order to better link this population to possible job locations. Moreover, defining the actual number of public transport dependent inhabitants solely based on non-related variables proves to be difficult. The use of factor analysis to group the variables and weight them according to their intercorrelation seeks to address this issue. However, to delineate the population that is truly public transport dependent, more detailed information on the individual level is needed.

Mainly due to computational complexity, several assumptions were made in the calculation of the accessibility index for the IPTP. The maximum travel time of 60 minutes is not fully sufficient for public transport, especially when ingress and egress times are taken into consideration. As a result, the method tends to favor inhabitants living in the vicinity of public transport stops, as their pre and post transport remains limited. Therefore, a fourth enhancement can apply a higher maximum travel time. In addition, it seems desirable to incorporate a more accurate weighting scheme in the calculation of the accessibility index. A linear weighting scheme is highly interpretable and easy to implement and it is considered as a reasonable representation of the travel impedance when calculating travel times (Schuurman et al., 2010). Nonetheless, more complex weighting functions such as a negative exponential or Gaussian function may be considered.

Finally, because the availability of public transport is an important instrument of social inclusion or exclusion, providing low tariffs and reliable service plays an important role in mode choice 
decision. This research did not consider tariffs for using public transportation nor measures of delays or on-time performance. It seems fruitful to incorporate these refinements into future research on public transport accessibility.

\section{Acknowledgement}

The financial support from the Agency for Innovation by Science and Technology (IWT) is gratefully acknowledged. Additionally, the authors would like to thank the anonymous referees for their constructive comments that significantly improved this paper.

\section{References}

Atkins, 2012. Accessibility Planning Policy: Evaluation and Future Direction - Final Report (2012).

Benenson, I., Martens, K., Rofe, Y., Kwartler, A., 2011. Public transport versus private car GISbased estimation of accessibility applied to the Tel Aviv metropolitan area. Annals of Regional Science 47, 499-515.

Currie, G., 2010. Quantifying spatial gaps in public transport supply based on social needs. Journal of Transport Geography 18, 31-41.

Delbosc, A., Currie, G., 2011. The spatial context of transport disadvantage, social exclusion and well-being. Journal of Transport Geography 19, 1130-1137.

Delmelle, E.C., Casas, I., 2012. Evaluating the spatial equity of bus rapid transit-based accessibility patterns in a developing country: The case of Cali, Colombia. Transport Policy 20, 36-46.

Doerner, K., Focke, A., Gutjahr, W.J., 2007. Multicriteria tour planning for mobile healthcare facilities in a developing country. European Journal of Operational Research 179, 10781096.

Duvarci, Y., Yigitcanlar, T., Mizokami, S., 2015. Transportation disadvantage impedance indexing: A methodological approach to reduce policy shortcomings. Journal of Transport Geography 48, 61-75.

Farber, S., Morang, M.Z., Widener, M.J., 2014. Temporal variability in transit-based accessibility to supermarkets. Applied Geography 53, 149-159.

Farber, S., Paez, A., Mercado, R.G., Roorda, M., Morency, C., 2011. A time-use investigation of shopping participation in three Canadian cities: is there evidence of social exclusion? Transportation 38, 17-44.

Golub, A., Martens, K., 2014. Using principles of justice to assess the modal equity of regional transportation plans. Journal of Transport Geography 41, 10-20.

Grengs, J., 2015. Nonwork Accessibility as a Social Equity Indicator. International Journal of Sustainable Transportation 9, 1-14.

Gutierrez, J., Garcia-Palomares, J.C., 2008. Distance-measure impacts on the calculation of transport service areas using GIS. Environment and Planning B-Planning \& Design 35, 480-503.

Hadas, Y., 2013. Assessing public transport systems connectivity based on Google Transit data. Journal of Transport Geography 33, 105-116.

Henry, K.A., Sherman, R., Farber, S., Cockburn, M., Goldberg, D.W., Stroup, A.M., 2013. The joint effects of census tract poverty and geographic access on late-stage breast cancer diagnosis in 10 US States. Health \& Place 21, 110-121.

Hine, J., Grieco, M., 2003. Scatters and clusters in time and space: implications for delivering integrated and inclusive transport. Transport Policy 10, 299-306.

Jaramillo, C., Lizarraga, C., Grindlay, A.L., 2012. Spatial disparity in transport social needs and public transport provision in Santiago de Cali (Colombia). Journal of Transport Geography 24, 340-357.

Kamruzzaman, M., Hine, J., 2011. Participation index: a measure to identify rural transport disadvantage? Journal of Transport Geography 19, 882-899. 
Karner, A., Niemeier, D., 2013. Civil rights guidance and equity analysis methods for regional transportation plans: a critical review of literature and practice. Journal of Transport Geography 33, 126-134.

Lei, T.L., Church, R.L., 2010. Mapping transit-based access: integrating GIS, routes and schedules. International Journal of Geographical Information Science 24, 283-304.

Levitas, R., Pantazis, C., Fahmy, E., Gordon, D., Lloyd, E., Patsios, D., 2007. The multidimensional analysis of social exclusion. University of East London, Bristol.

Lucas, K., 2011. Making the connections between transport disadvantage and the social exclusion of low income populations in the Tshwane Region of South Africa. Journal of Transport Geography 19, 1320-1334.

Lucas, K., 2012. Transport and social exclusion: Where are we now? Transport Policy 20, 105113.

Ma, T., Jan-Knaap, G., 2014. Analyzing Employment Accessibility in a Multimodal Network using GTFS: A Demonstration of the Purple Line, Maryland, The Association of Collegiate Schools of Planning (ACSP) Annual Conference, Philadelphia, Pennsylvania.

Mackett, R.L., Achuthan, K., Titheridge, H., 2008. AMELIA: A tool to make transport policies more socially inclusive. Transport Policy 15, 372-378.

Mavoa, S., Witten, K., McCreanor, T., O'Sullivan, D., 2012. GIS based destination accessibility via public transit and walking in Auckland, New Zealand. Journal of Transport Geography 20, $15-22$.

McCray, T., Brais, N., 2007. Exploring the role of transportation in fostering social exclusion: The use of GIS to support qualitative data. Networks \& Spatial Economics 7, 397-412.

Owen, A., Levinson, D.M., 2014. Modeling the Commute Mode Share of Transit Using Continuous Accessibility to Jobs, 93rd Annual Meeting of the Transportation Research Board, Washington D.C.

Paez, A., Mercado, R.G., Farber, S., Morency, C., Roorda, M., 2010. Relative Accessibility Deprivation Indicators for Urban Settings: Definitions and Application to Food Deserts in Montreal. Urban Studies 47, 1415-1438.

Paez, A., Scott, D.M., Morency, C., 2012. Measuring accessibility: positive and normative implementations of various accessibility indicators. Journal of Transport Geography 25, 141-153.

Porter, G., Hampshire, K., Abane, A., Munthali, A., Robson, E., Mashiri, M., Tanle, A., Maponya, G., Dube, S., 2012. Child Porterage and Africa's Transport Gap: Evidence from Ghana, Malawi and South Africa. World Development 40, 2136-2154.

Preston, J., Raje, F., 2007. Accessibility, mobility and transport-related social exclusion. Journal of Transport Geography 15, 151-160.

Priya, T., Uteng, A., 2009. Dynamics of transport and social exclusion: Effects of expensive driver's license. Transport Policy 16, 130-139.

Ritsema van Eck, J., Burghouwt, G., Dijst, M., 2005. Lifestyles, spatial configurations and quality of life in daily travel: an explorative simulation study. Journal of Transport Geography 13, 123-134.

Schönfelder, S., Axhausen, K.W., 2003. Activity spaces: measures of social exclusion? Transport Policy 10, 273-286.

Schuurman, N., Bérubé, M., Crooks, V.A., 2010. Measuring potential spatial access to primary health care physicians using a modified gravity model. Canadian Geographer / Le Géographe canadien 54, 29-45.

Stanley, J., Vella-Brodrick, D., 2009. The usefulness of social exclusion to inform social policy in transport. Transport Policy 16, 90-96.

Welch, T.F., Mishra, S., 2013. A measure of equity for public transit connectivity. Journal of Transport Geography 33, 29-41.

Wu, B.M., Hine, J.P., 2003. A PTAL approach to measuring changes in bus service accessibility. Transport Policy 10, 307-320. 